
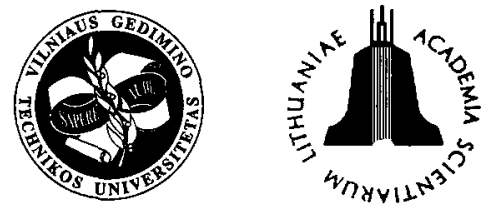

JOURNAL OF CIVIL ENGINEERING AND MANAGEMENT

http:/www.vtu.lt/english/editions

2003, Vol IX, No 2, 139-145

\title{
SOME PRELIMINARY RESULTS ON ANALYSIS OF CONCRETE FLEXURAL MEM- BERS WITH HYBRID REINFORCEMENTS
}

\author{
Hau Y. Leung \\ Dept of Building and Construction, City University of Hong Kong, Tat Chee Avenue, Kowloon, \\ Hong Kong SAR, China.E-mail: bchyl@cityu.edu.hk
}

Received 07 Oct 2002; accepted 16 Jan 2003

\begin{abstract}
It is generally accepted that conventional steel reinforced concrete (RC) flexural members usually fails in a ductile mode with low load-carrying capacity. In contrast, recent introduction of fibre-reinforced-polymer (FRP) rods into RC beams gives rise to a higher ultimate load but it lacks ductility. It is anticipated that a hybrid combination of conventional steel rebars and novel FRP rods as reinforcing materials in concrete beam can provide a strong and ductile beam characteristics. Prior to the experimental verifications, a preliminary analytical study is carried out. The analytical model describes some features of the flexural behaviour of concrete members reinforced with hybrid reinforcing materials. The model implementation is based on the use of the true stress-strain relationships for plain concrete, steel rebar and FRP rod. The main variable considered in present study is the arrangement of steel rebars and FRP rods. This paper presents some particular findings from the model. Most results are also compared with that of concrete beam reinforced only with steel rebars.
\end{abstract}

Keywords: concrete, RC beam, reinforcement, steel rebar, FRP rod, flexural strength.

\section{Introduction}

The cost of fibre reinforced polymer (FRP) composite remains several times higher than that of steel despite the fact that the cost of FRP keeps on decreasing in recent years. Notwithstanding the cost issue, many researchers have endeavoured to investigate the structural performance of FRP reinforced concrete (RC) components [1-8]. A lot of pilot structures have also been built in many countries [9-10]. Unfortunately, many investigations showed that the failure of FRP RC beams was usually sudden with a limited ductility. Under-reinforced FRP beams using a FRP cross-sectional area less than the balanced reinforcement area failed with a FRP rupture. In contrast, over-reinforced FRP RC beams with the FRP area larger than the balanced one indicated a concrete crushing failure mode. It is apparent that these two failure modes are brittle and no signs of warning will be provided prior to failure. In order to improve the member's ductility and to prevent the collapse of structures, confinement of compression concrete and hybrid use of FRP rods and steel rebars are two possible methods. Previous tests on concrete columns and concrete beams reinforced with confinement (in the form of steel stirrups and FRP spirals) have illustrated the effectiveness in strain and strength enhancements of the RC member [11]. Comparatively speaking, work related to a hybrid use of FRP rods and steel rebars is rare [12].
In the past, studies related to the strengthening of steel RC structural members have indicated that the application of FRP rods near the surface of the member (commonly referred to as near-surface mounted FRP rods) was successful in promoting the flexural capacity of the member [13-14]. Instead of using FRP rods for strengthening purposes, FRP rods and steel rebars are adopted in initial beam design in the present study. Tentatively, concrete beams reinforced with both steel rebars and FRP rods exhibit one of the following flexural failure modes:

- Concrete crushing occurs before steel yields and FRP breaks.

- Steel yields followed by concrete crushing while FRP remains intact.

- Steel yields followed by steel breaks while FRP remains intact.

- Steel yields followed by FRP snaps.

These failure modes depend largely on the material properties of the ingredients and the configuration of the beam section. It is apparent that the first failure mode occurs only in over-reinforced sections. Since the aim of this study is to investigate the effect of addition of FRP rods into the steel-reinforced section, the latter three failure modes are desired. In this paper, an analytical model is generated to compute the flexural behaviour of concrete section reinforced with conventional steel reinforcing bars and novel FRP rods. Some results, including 
the strains, neutral axis depth, moments and curvatures, are discussed.

\section{Analysis}

A simple analytical procedure is developed to calculate the strains and stresses in concrete and reinforcements, moment and curvature in a rectangular concrete cross-section reinforced with steel rebars and FRP rods. The procedure, which is derived from force equilibrium and strain compatibility, is applicable to conventional steel reinforced sections, FRP reinforced sections, as well as concrete sections reinforced with a combination of steel rebars and FRP rods. Fig 1 shows the rectangular concrete beam section used in this study. The basic assumptions made include (1) linear strain distribution across the depth of section, (2) no bond slip of reinforcement, (3) reinforcement stress can be obtained from its stress-strain relationship, (4) tension concrete ignored, (5) shear deformation neglected and (6) failure of section is defined by either concrete crushing or reinforcement snapping.

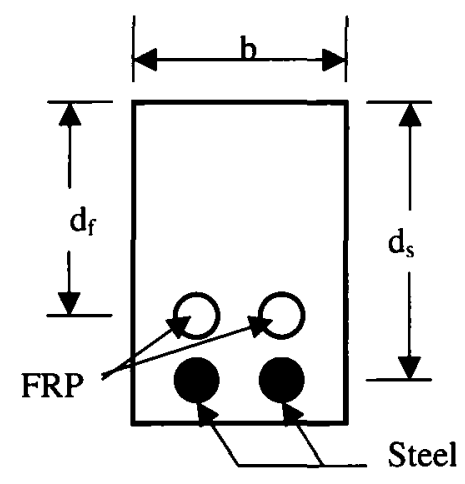

Fig 1. Beam cross-section

\section{Stress-strain relations}

\subsection{Concrete in compression}

The nonlinear stress-strain model of concrete in compression developed by Almusallam and Alsayed [15] is used. This model was found to fit well the experimental results for normal strength and high strength concretes. In the model, the relationship between concrete stress $\left(\sigma_{c}\right)$ and concrete strain $\left(\varepsilon_{c}\right)$ is expressed by Eq 1 .

$$
\sigma_{c}=\frac{\left(K-K_{p}\right) \varepsilon_{c}}{\left[1+\left(\frac{\left(K-K_{p}\right) \varepsilon_{c}}{\sigma_{0}}\right)^{n}\right]^{\frac{1}{n}}}+K_{p} \varepsilon_{c},
$$

where $K$ - initial slope of the curve; $K_{p}$ - final slope of the curve; $\sigma_{0}$ - reference stress; and $n$ - curveshape parameter. The equations of all these model parameters are given as follows.

$$
\begin{gathered}
n=-\frac{\ln 2}{\ln \left(\frac{\sigma_{1}}{\sigma_{0}}-\frac{K_{p}}{K-K_{p}}\right),} \\
\sigma_{1}=\sigma_{c}^{\prime}\left[\left(\begin{array}{l}
\varepsilon_{1} \\
\varepsilon_{0}
\end{array}\right)-\left(\begin{array}{l}
\varepsilon_{1} \\
\varepsilon_{0}
\end{array}\right)^{2}\right], \\
\varepsilon_{1}=\begin{array}{c}
\sigma_{0} \\
K-K_{p}
\end{array} \\
\sigma_{0}=5,6+1,02 \sigma_{c}^{\prime}-K_{p} \varepsilon_{0},
\end{gathered}
$$

for

$$
\sigma_{c}^{\prime} \leq 55 \mathrm{MPa}
$$

$$
K_{p}=5470-375 \sigma_{c}^{\prime},
$$

for

$$
\sigma_{c}^{\prime}>55 \mathrm{MPa}
$$

$$
K_{p}=16398,23-676,82 \sigma_{c}^{\prime},
$$

$$
K=3320 \sqrt{\sigma_{c}^{\prime}}+6900
$$$$
\varepsilon_{0}=\left(0,2 \sigma_{c}^{\prime}+13,06\right) \times 10^{-4},
$$

where the ultimate compressive strength of concrete $\left(\sigma_{c}^{\prime}\right)$ is in $\mathrm{MPa}$.

Fig 2 shows a stress-strain curve of compression concrete where the ultimate concrete strength $\sigma_{c}^{\prime}=50$ $\mathrm{MPa}$. As can be seen in Fig 2, the stress-strain curve terminates at an assumed strain value of 0,0035 .

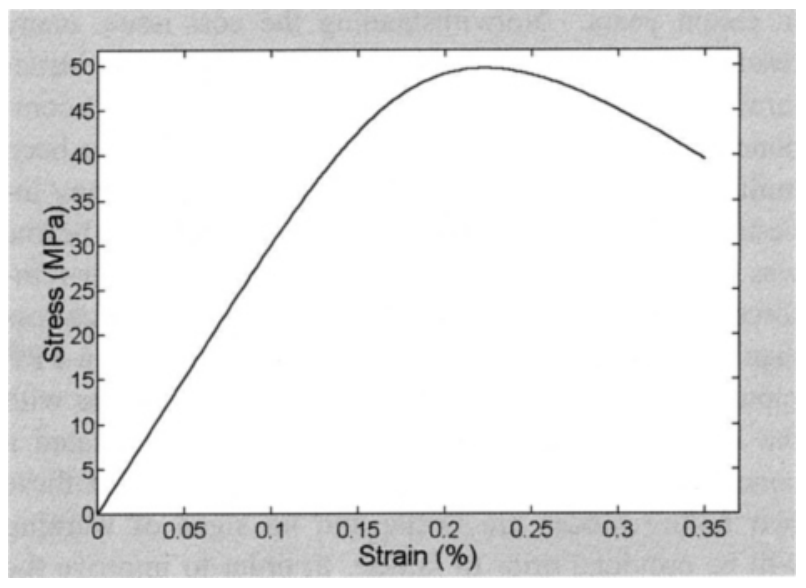

Fig 2. Stress-strain curve for concrete in compression

\subsection{Tensile steel embedded in concrete}

The stress-strain curve of steel reinforcing bars embedded in concrete is assumed to be bi-linear and was modelled by Wang and Hsu [16]. The relationship between steel stress $\left(\sigma_{s}\right)$ and steel strain $\left(\varepsilon_{s}\right)$ can be expressed by the following two equations (Eqs 2, 3): 
for

$$
\varepsilon_{s} \leq \varepsilon_{n}, \quad \sigma_{s}=E_{s} \varepsilon_{s},
$$

for

$$
\varepsilon_{s}>\varepsilon_{n},
$$

$$
\sigma_{s}=\sigma_{y}\left[(0,91-2 B)+(0,02+0,25 B) \frac{\varepsilon_{s}}{\varepsilon_{y}}\right] \text {, }
$$

where $E_{s}$ - elastic modulus of steel; $\sigma_{y}$ - yield stress of steel; $B$ - stress parameter; $\varepsilon_{y}$ - strain of steel at yield; and $\varepsilon_{n}-$ strain of steel at average stress when initial yielding occurs. All the model parameters are given as follows:

$$
\begin{gathered}
\varepsilon_{n}=\varepsilon_{y}(0,93-2 B), \\
B=\frac{\left(\sigma_{c r} / \sigma_{y}\right)^{1,5}}{\rho}, \\
\rho=\begin{array}{c}
A_{s} \\
b d_{s}
\end{array} 0,5 \%, \\
\sigma_{c r}=0,31 \sqrt{\sigma_{c}^{\prime}},
\end{gathered}
$$

where $\sigma_{c}^{\prime}$ and the cracking strength $\left(\sigma_{c r}\right)$ are in $\mathrm{MPa}$.

This model, unlike others, accounts for the fact that the stresses in the steel bars between concrete cracks will be less than the yield stress at the cracks. An averaged value of steel stress across the cracks is thus adopted.

To facilitate generating a curve, some parameters are assumed and they include the breadth of concrete section $(b=200 \mathrm{~mm})$; depth of steel rebars $\left(d_{s}=\right.$ $300 \mathrm{~mm}$ ); area of steel $\left(A_{s}=157 \mathrm{~mm}^{2}\right)$; yield stress $\left(\sigma_{y}=420 \mathrm{MPa}\right)$; and elastic modulus $\left(E_{s}=200 \mathrm{GPa}\right)$. The resulting curve is shown in Fig 3.

\subsection{Tensile FRP rod}

The relationship of FRP stress $\left(\sigma_{f}\right)$ and FRP strain $\left(\varepsilon_{f}\right)$ under tension is assumed to be linear and is defined by Eqs 4, 5 .

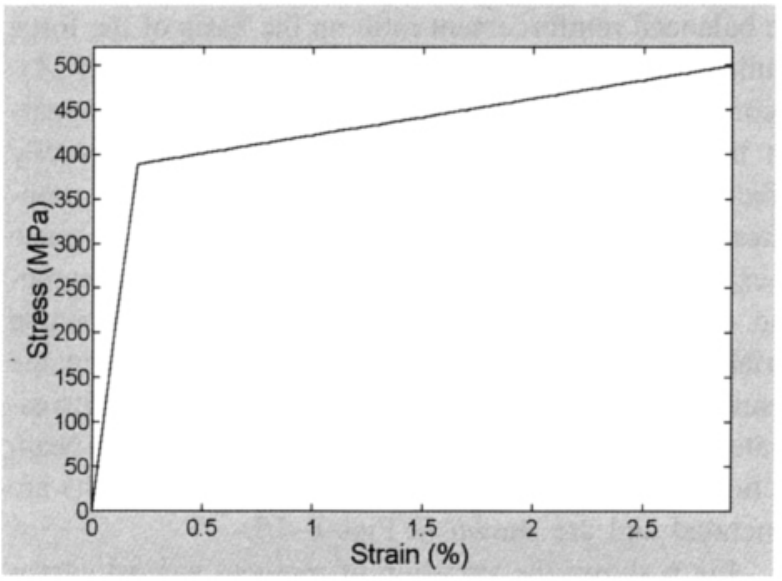

Fig 3. Stress-strain curve for steel

$$
\begin{aligned}
& \text { for } \quad \varepsilon_{f} \leq \varepsilon_{f}^{u} \quad \sigma_{f}=E_{f} \varepsilon_{f}, \\
& \text { for } \quad \varepsilon_{f}>\varepsilon_{f}^{u} \quad \sigma_{f}=0,
\end{aligned}
$$

where $E_{f}$ denotes the elastic modulus of FRP.

The three common FRPs used in construction industry are C(carbon)FRP, A(aramid)FRP and G(glass) FRP, and some of their properties (values obtained from Leung and Burgoyne [17]) are given in Table. Using these values, the stress-strain curves for the three FRPs can then be generated and they are illustrated in Fig 4 .

Properties of FRPs

\begin{tabular}{|c|c|c|c|}
\hline Materials & CFRP & AFRP & GFRP \\
\hline Elastic modulus $E_{f}$ & $168 \mathrm{GPa}$ & $67 \mathrm{GPa}$ & $48 \mathrm{GPa}$ \\
\hline Ultimate strain $\varepsilon_{f}^{u}$ & 0,017 & 0,021 & 0,023 \\
\hline
\end{tabular}

\section{Derivations}

A strain incremental technique is used in the derivation of different parameters. The strain in the extreme fibre of concrete $\left(\varepsilon_{c}^{t o p}\right)$ is increased in a fixed increment, from zero to the ultimate (failure) strain value, to generate the moment-curvature relationship. Fig 5 shows the distributions of strain and stress across the cross-section.

Once the value of $\varepsilon_{c}^{t o p}$ is determined, a value of $c$ is assumed. The compression concrete is divided into layers. Strains in the $i^{\text {th }}$ compression concrete layer $\left(\varepsilon_{c}^{i}\right)$, FRP rods $\left(\varepsilon_{f}\right)$ and steel rebars $\left(\varepsilon_{s}\right)$ are then calculated, in terms of $\varepsilon_{c}^{t o p}$, by the following three equations (Eqs 6 to 8 ):

$$
\varepsilon_{c}^{i}=\varepsilon_{c}^{t o p} \times\left(\begin{array}{c}
y_{i} \\
c
\end{array}\right)
$$

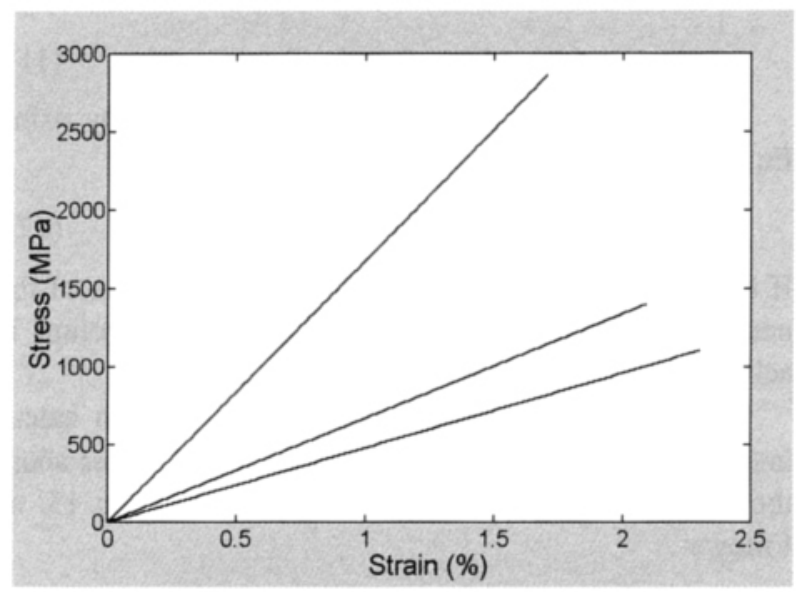

Fig 4. Stress-strain curve for FRP 


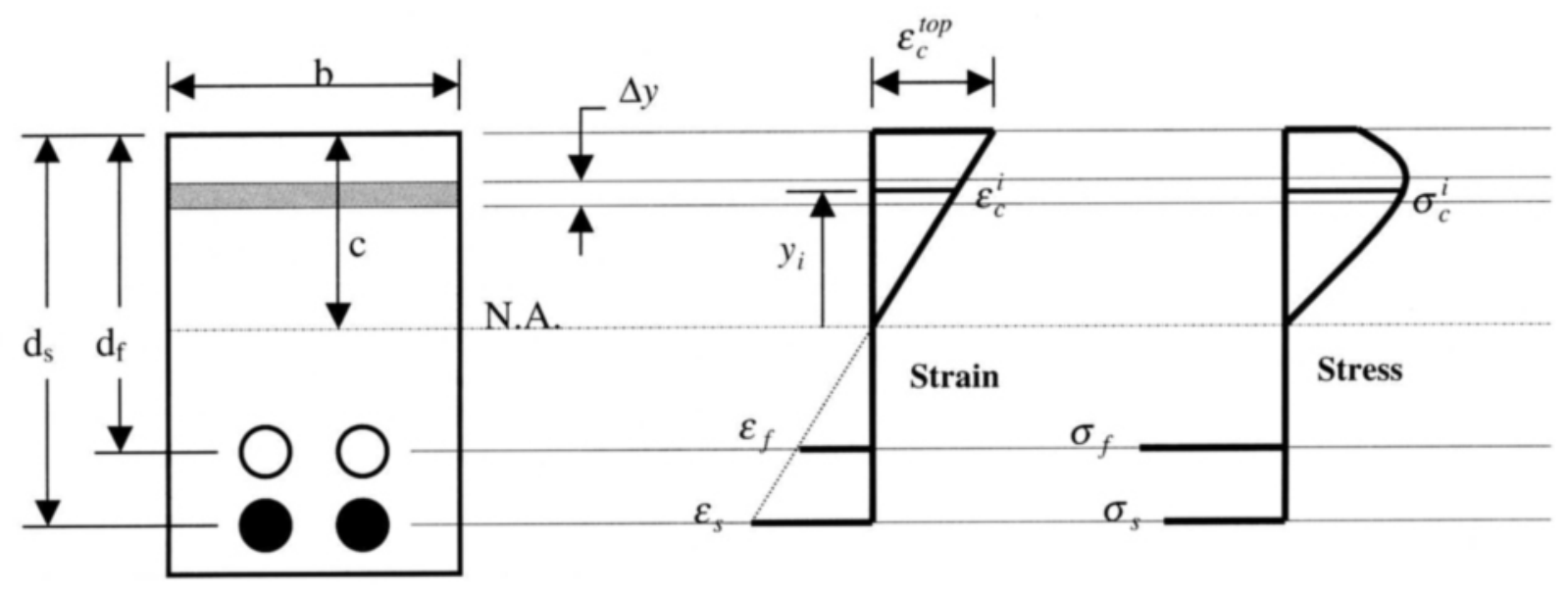

Fig 5. Strain and stress distributions

$$
\begin{gathered}
\varepsilon_{f}=\varepsilon_{c}^{o p} \times\left(\frac{d_{f}-c}{c}\right), \\
\varepsilon_{s}=\varepsilon_{c}^{t o p} \times\left(\begin{array}{c}
d_{s}-c \\
c
\end{array}\right),
\end{gathered}
$$

where $y_{i}$ is the distance of the $i^{\text {th }}$ concrete layer measured from the neutral axis; $c$ - the depth of neutral axis; $d_{f}$ and $d_{s}$ - the depth of FRP rods and steel rebars respectively. The stresses in the $i^{\text {th }}$ concrete layer $\left(\sigma_{c}^{i}\right)$, FRP rods $\left(\sigma_{f}\right)$ and steel rebars $\left(\sigma_{s}\right)$ are found from the corresponding stress-strain curves.

The concrete compressive force $\left(F_{c}\right)$ is determined by summation of the product of elemental stress and the corresponding elemental area $(b \times \Delta y)$ over the entire compression concrete portion. It is expressed by $\mathrm{Eq} 9$.

$$
F_{c}=\sum_{i}\left(\sigma_{c}^{i} \times b \times \Delta y\right) .
$$

The tensile FRP force $\left(F_{f}\right)$ and steel force $\left(F_{s}\right)$ are found by multiplying the FRP stress by the FRP area $\left(A_{f}\right)$ and the steel stress by the steel area $\left(A_{s}\right)$ respectively (Eqs 10, 11).

$$
\begin{gathered}
F_{f}=\sigma_{f} \times A_{f}, \\
F_{s}=\sigma_{s} \times A_{s} .
\end{gathered}
$$
Eq 12:

Equilibrium of internal forces is imposed by using

$$
F_{c}=F_{f}+F_{s} .
$$

If the above equation is not satisfied, the location of the neutral axis $(c)$ is adjusted until force equilibrium is achieved.

The internal resisting moment $(M)$ is then calculated by summing the moments of all internal forces about the neutral axis, and it can be expressed, by $\mathrm{Eq} \mathrm{13}$, as follows:

$$
M=\sum_{i}\left(\sigma_{c}^{i} \times b \times \Delta y\right) y_{i}+F_{f} \times\left(d_{f}-c\right)+F_{s} \times\left(d_{s}-c\right)
$$

As indicated by Eq 14, the curvature $(\kappa)$ is also found by dividing the extreme concrete fibre strain by the neutral axis depth

$$
\kappa=\begin{gathered}
\varepsilon_{c}^{t o p} \\
c
\end{gathered} .
$$

A small increment on $\varepsilon_{c}^{t o p}$ is applied and the procedure repeats. The analysis terminates when $\varepsilon_{c}^{t o p}$ goes beyond 0,0035 .

\section{Results and discussion}

To generate analytical results from the above procedure, some material and geometric parameters are assumed. To do this, the model parameters used in generating the curves in Figs 2, 3 are adopted, GFRP is chosen as the internal reinforcement and its properties are obtained in Table 1. It should be noted that a breaking strain of $10 \%$ is imposed for tensile steel rebars embedded in concrete. To determine the amount of FRP bars used in the section $\left(A_{f}\right)$, it is more rational to calculate the balanced reinforcement ratio on the basis of the force equilibrium across the section first and then select $A_{f}$ according to the desired section behaviour. It is apparent that the amount and position of FRP bars heavily affect the section behaviour and all of the section properties are driven by these two variables. In the absence of experimental data, $A_{f}=A_{s}$ is assumed. This assumption clearly leads to a condition that only one single variable - depth of GFRP rods $\left(d_{f}\right)$ is left and in the ensuing investigation this value is altered so as to investigate its effect on the flexural behaviour of the beam section (as shown in Fig 1). Some analytical results are generated and are shown in Figs 6-10.

Fig 6 shows the variation of moment against curvature for different values of $d_{f}$, the curve for no GFRP 


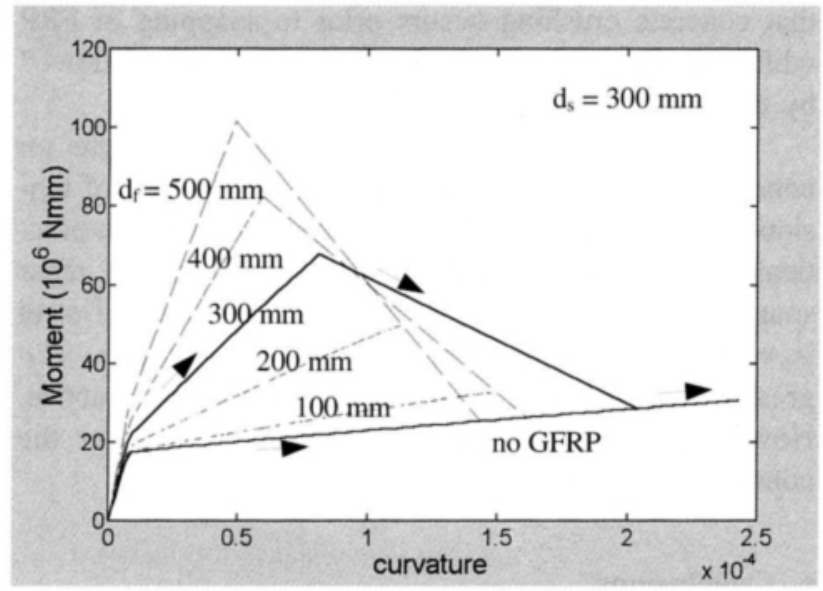

Fig 6. Moment against curvature

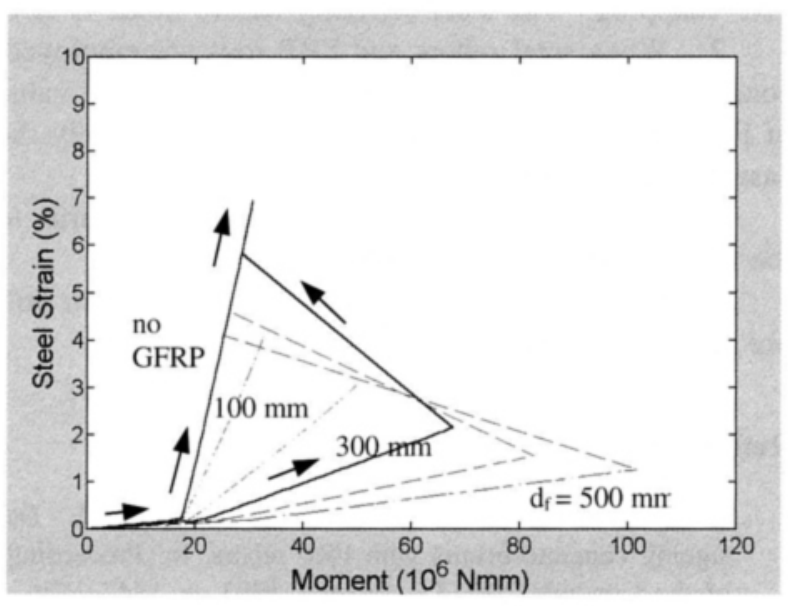

Fig 8. Steel strain against moment

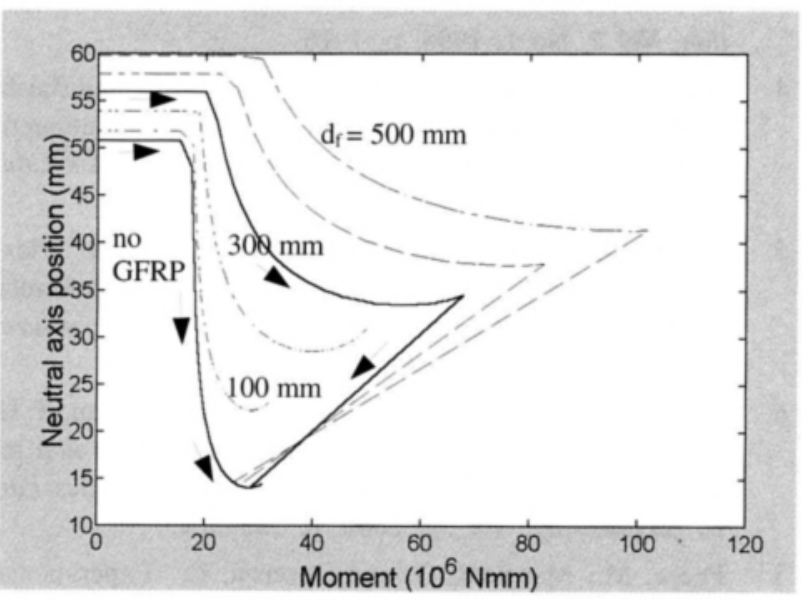

Fig 10. Neutral axis depth against moment

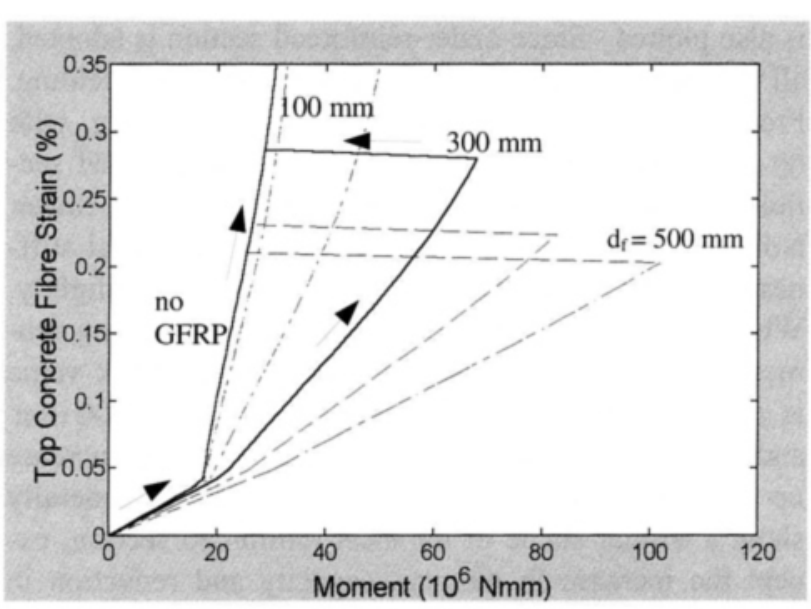

Fig 7. Concrete strain against moment

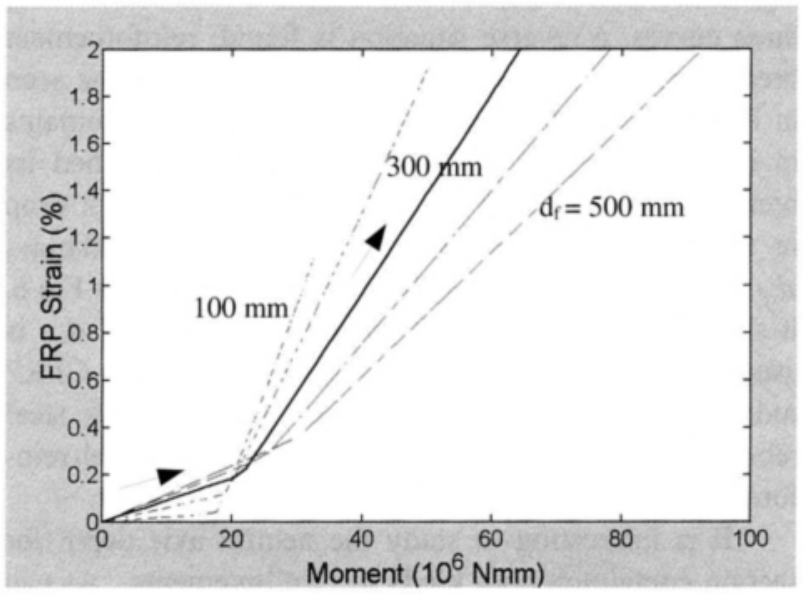

Fig 9. GFRP strain against moment

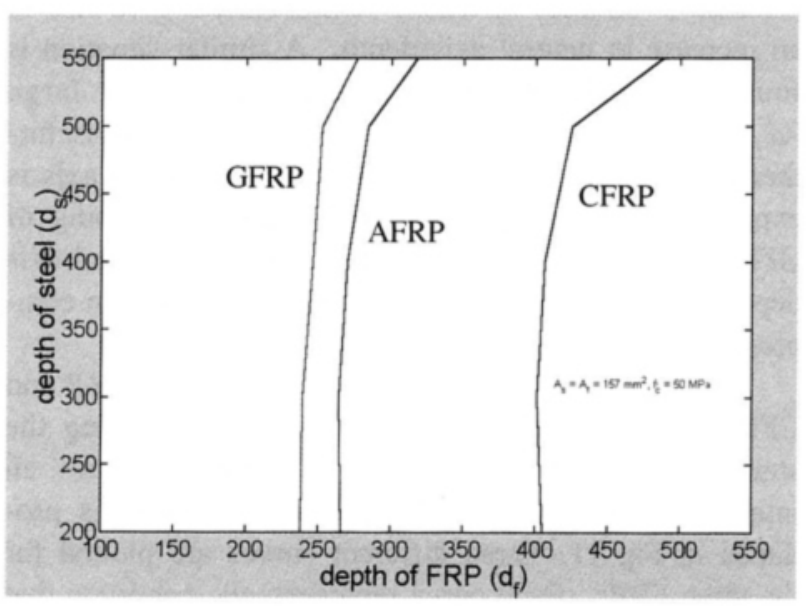

Fig 11. $d_{s}$ versus $d_{f}$ 
is also plotted. Since under-reinforced section is adopted, all different sections show occurrence of steel yielding. From the figure, it is clear that the beam section, with no GFRP, becomes a conventional steel-reinforced section and its moment-curvature relationship is bi-linear. Notice that when GFRP rods are added, the initial stiffness and the yield moment seem to increase slightly. When larger value of $d_{f}$ is adopted, the resisting moment increases in a faster way and a higher peak value is resulted. When the two curves with $d_{f}=100 \mathrm{~mm}$ and $d_{f}=200 \mathrm{~mm}$ are considered, they show an increase up to a peak and then stop. The two curves generally show a similar shape of the steel-reinforced section, except the increase in moment capacity and reduction in ductility. From Figs 7 to 9 , it can be seen that the strains of steel bars and GFRP rods for $d_{f}=100 \mathrm{~mm}$ and $d_{f}=200 \mathrm{~mm}$ are smaller than their corresponding ultimate strain values, while the concrete strain increases rapidly to 0,0035 . This demonstrates that concrete crushing occurs before steel or FRP snaps. For the remaining three curves, a reverse situation is found; reinforcement breaks before concrete crushing occurs. As can be seen in Figs 8, 9 and 10, the variation of steel strain remains in its plastic range while GFRP rods have reached its breaking point at failure. This explains the abrupt drop in moment-curvature relationship for $d_{f}=300 \mathrm{~mm}$, $d_{f}=400 \mathrm{~mm}$ and $d_{f}=500 \mathrm{~mm}$, as indicated in Fig 6 . It should also be noted that when larger value of $d_{f}$ is used, the decrease in moment is more rapid. After GFRP rods have broken, the beam section contains only steel rebars and the moment-curvature curve for steel-reinforced section is followed.

It is interesting to study the neutral axis depth for section containing both kinds of reinforcements. As can be seen in Fig 10, when no GFRP is used, the neutral axis remains fairly constant. Upon loading, it shifts upward when yielding of steel occurs. The neutral axis slightly goes downward when the section is about reaching its failure stage, this is explained by the fact that a reduction in concrete stress after its peak value and an increase in stresses in tensile reinforcement give rise to an increase in neutral axis depth. A similar situation is found when the depth of GFRP rods is not large ( $d_{f}=100 \mathrm{~mm}$ and $d_{f}=200 \mathrm{~mm}$ ). When $d_{f}$ is further increased, an abrupt upward shift in neutral axis is expected since the failure is governed by snapping of GFRP. Once the GFRP loses its action, the neutral axis depth must be reduced to balance the force between compression concrete and remaining steel rebars.

A similar analysis can be carried out for AFRP and CFRP using values in Table 1 . Instead of plotting the strains, neutral axis depths, moments and curvatures, an interaction diagram for different failure modes is produced in Fig 11. Three different curves are plotted for the three FRPs. Each curve represents the condition that concrete crushing and breaking of FRP rods break simultaneously. The area to the left of the curve indicates that concrete crushing occurs prior to snapping of FRP while the area to the right suggests FRP breaks followed by concrete crushing.

The current investigation provides some results on concrete flexural members reinforced with a mix of tension reinforcements, but there are limitations from a practical point of view. Firstly, it is rare to have steel rebar snapped at ultimate state as the breaking strain of steel is very much in excess of that for FRP. Besides, $d_{f}$ greater than $300 \mathrm{~mm}$ is not common in daily practice. However, these two conditions are considered for the completeness of study.

\section{Conclusions}

From the analytical results, it is possible to conclude that:

1. Failure of steel-reinforced section with adddition of FRP rods is usually governed by concrete crushing or FRP snapping. The steel breaking failure mode is rare.

2. When steel rebars and FRP rods are employed, concrete crushing is usually accompanied by small value of FRP depth whereas breaking of FRP is normally the case for large value of FRP depth.

3. When FRP snaps, the beam section returns to the conventional steel-reinforced section.

4. Interaction diagram, which shows different failure modes, is produced.

\section{References}

1 Granga Rao, H. V. S.; Faza, S. S. and Anderson, A. Designing concrete beams with FRP rebars. In: Proceedings of the Concrete 2000 Conference, 1993, p. 1847-1856.

2 Benmokrane, B.; Chaalial, O. and Masmoudi, R. Glass fibre reinforced plastic (GFRP) rebars for concrete structures. Construction and Building Materials, Vol 9, No 6, 1995, p. 353-364.

3 Theriault, M. and Benmokrane, B. Effects of FRP reinforcement ratio and concrete strength on flexural behaviour of concrete beams. Journal of Composites for Construction, Vol 2, No 1, 1998, p. 7-16.

4 Grace, N. F.; Soliman, A. K.; Abdel-Sayed, G. and Saleh, K. R. Behaviour and ductility of simple and continuous FRP reinforced beams. Journal of Composites for Construction, Vol 2, No 4, 1998, p. 186-194.

5 Masmoudi, R.; Theriault, M. and Benmokrane, B. Flexural behaviour of concrete beams reinforced with deformed fiber reinforced plastic reinforcing rods. $A C I$ Structural Journal, Vol 95, No 6, 1998, p. 665-676.

6 Alsayed, S. H.; Al-Salloum, Y. A. and Almusallam, T. H. Performance of glass fiber reinforced plastic bars as a reinforcing material for concrete structures. Composites Part $B$ : Engineering, Vol 31, 2000, p. 555-567.

7 Peece, M.; Manfredi, G. and Cosenza, E. Experimental response and code models of GFRP RC beams in bending. Journal of Composites for Construction, Vol 4, No 4, 2000 , p. $182-190$. 
8 Toutanji, H. and Saafi, M. Flexural behavior of concrete beams reinforced with glass fiber-reinforced polymer (GFRP) bars. ACI Structural Journal, Vol 97, No 5, 2000, p. 712-719.

9 Balendran, R. V.; Rana, T. M.; Maqsood, T. and Tang, W. C. Application of FRP bars as reinforcement in civil engineering structures. Structural Survey, Vol 21, No 2, 2002, p. 62-72.

10 Clarke, J. L. Alternative Materials for the Reinforcement and Prestressing of Concrete. Chapman \& Hall Inc., Chapter 7, 1993, p. 151-171.

11 Leung, H. Y. and Burgoyne, C. J. Compressive behaviour of concrete confined by aramid fibre spirals. In: Proceedings of the international conference on structural engineering, mechanics and computation-SEMC 2001, Cape Town, South Africa, 2001, p. 1357-1364.

12 Aiello, M. A. and Ombres, L. Structural performances of concrete beams with hybrid (fiber-reinforced polymer-steel) reinforcements. Journal of Composites for Construction, Vol 6, No 2, 2002, p. 133-140.

13 Carolin, A.; Nordin, H. and Taljsten, B. Concrete beams strengthened with near surface mounted reinforcement of
CFRP. In: Proceedings of the International Conference on FRP Composites in Civil Engineering- CICE 2001, Hong Kong, 2001, p. 1059-1066.

14 Nordin, H.; Taljsten, B. and Carolin, A. Concrete beams strengthened with prestressed near surface mounted reinforcement (NSMR). In: Proceedings of the international conference on FRP composites in civil engineering- CICE 2001, Hong Kong, 2001, p. 1067-1075.

15 Almusallam, T. H. and Alsayed, S. H. Stress-strain relationship of normal, high-strength and lightweight concrete. Magazine of concrete research, Vol 47, No 170, 1995, p. 39-44.

16 Wang, T. and Hsu, T. T. C. Nonlinear finite element analysis of concrete structures using new constitutive models. Computers and Structures, Vol 79, 2001, p. 2781-2791.

17 Leung, H. Y. and Burgoyne, C. J. Analysis of FRP-reinforced concrete beam with aramid spirals as compression confinement. In: Proceedings of the international conference on structural engineering, mechanics and computation, Cape Town, South Africa, ed by A. Zingoni, Elsevier. 1, 2001, p. 335-342. 